See discussions, stats, and author profiles for this publication at: https://www.researchgate.net/publication/340896981

\title{
How team averages in authentic living and perspective-taking personalities relate to team information elaboration and team performance
}

Article in Journal of Applied Psychology · April 2020

DOI: $10.1037 /$ apl0000499

CITATIONS

0

4 authors, including:

Hannes Leroy

Erasmus University Rotterdam

22 PUBLICATIONS 151 CITATIONS

SEE PROFILE

Anja Van den Broeck

KU Leuven

108 PUBLICATIONS 4,899 CITATIONS

SEE PROFILE

Some of the authors of this publication are also working on these related projects:

Motivation at work: A dynamic approach to performance and well-being View project

Project Motivation View project
READS

234

Kathleen Vangronsvelt

KU Leuven

2 PUBLICATIONS 12 CITATIONS

SEE PROFILE 


\title{
How Team Averages in Authentic Living and Perspective Taking Personalities Relate to Team Information Elaboration and Team Performance.
}

\author{
Hannes Leroy \\ Erasmus University Rotterdam \\ Inga J. Hoever \\ Erasmus University Rotterdam \\ Kathleen Vangronsvelt \\ Antwerp Management School, KU Leuven \\ Anja Van den Broeck \\ KU Leuven and North West University
}

Acknowledgements: We gratefully acknowledge input from Verena Krause for our work and grant support from KU Leuven (VKH-C9278-StG/ 14/035). 


\section{Abstract}

Is it wise to be authentic, that is, to express your inner thoughts and feelings, in a team context? Although authenticity can be argued to benefit teamwork as authentic team members contribute their unique perspectives, it can also hinder teamwork if those unique perspectives are not heard and integrated. Using theory on groups as information processors, we propose that when team members both contribute their own unique perspectives (team mean authentic living), and try to understand each other's contributions (team mean perspective taking), a process of information elaboration occurs at the team level, which in turn leads to team performance. Study 1 tested these assumptions in 67 teams of students $(\mathrm{N}=247)$, whereas Study 2 used 37 teams of employees $(N=194)$. Results support the hypothesized interaction between team mean authentic living and team mean perspective taking on team information elaboration such that the effects were positive when perspective taking was high but negative when it was low. In terms of team performance, although team information elaboration consistently predicted team performance in both studies, Study 1 could not confirm the hypothesized indirect effects, whereas Study 2 confirmed only the hypothesized positive indirect effect. (PsycInfo Database Record (c) 2020 APA, all rights reserved)

In the fourth century BC, Aristotle urged his contemporary citizens to live in concert with their true, inner selves in order to live a worthy life (Kernis \& Goldman, 2006). Ever since, the advice to 'thine own self be true!' (Shakespeare, Hamlet) has been reiterated by outstanding psychologists (e.g., James, 1890; Maslow, 1968; Rogers, 1961) and has remained prominent in Western societies (e.g., Slabu, Lenton, Sedikides, \& Bruder, 2014), with the popular press regularly advocating that acting authentically is an invaluable currency for professional success (George, 2003; George \& Sims, 2007; Rosenbloom, 2011). In this article, we revisit the advice to 'just be yourself' in light of an increasingly reliance on interdependent teamwork in contemporary workplaces (Homan, van Knippenberg, van Kleef, \& De Dreu, 2007; Jehn, Northcraft, \& Neale, 1999; Salas, Goodwin, \& Burke, 2008) and ask how the self-oriented notion of being true to oneself affects team functioning.

Prior individual-level work seems to support the advice that expressing yourself authentically at work improves personal well-being, leading to more resilience to burnout, less distress, more work engagement, and more subjective career success (Baugh \& Sullivan, 2012; Erickson \& Ritter, 2001; Leroy, Anseel, Dimitrova, \& Sels, 2013). However, these results largely fail to address whether behaving authentically also benefits work-related interpersonal interactions and outcomes. In this study, we contribute to the stream of research that moves beyond the intrapersonal benefits of authenticity (e.g., Gino, Sezer, \& Huang, in press) and consider the social benefits as well as potential liabilities of being authentic in the workplace (Cha et al., 2019). Specifically, in this paper, we add to previous work by investigating the role of authenticity for effective functioning at the team level.

In an interdependent work setting (Ilgen, Hollenbeck, Johnson, \& Jundt, 2005), there are valid reasons to believe that authenticity in and off itself may both help and hinder team functioning. On the one hand, being authentic makes team members more likely to reveal their unique thoughts and emotions. This strengthens their individual input to the team which can benefit 
the team's completion of its interdependent tasks. On the other hand, a strong focus on sharing unique information and/or perspectives may come at the expense of the team's ability to pay attention to and process all the information that is authentically presented. Following the groups as information processors model which highlights the joint need for both members' contributions and teams' ability to combine members' input (Hinsz, Tindale, \& Vollrath, 1997), we propose that perspective taking in the team can help to mitigate the potentially adverse effects of team members' authenticity on team outcomes. We propose that both offering one's unique perspective as well as the ability to listen to and integrate other's unique perspectives are essential ingredients for team information elaboration and - hence - team performance.

To capture the presence of both ingredients in the team, we focus on team averages in authentic living (i.e., the tendency to express one's authentic self in the workplace; Wood, Linley, Maltby, Baliousis, \& Jospeh, 2008;) and team averages in perspective taking personality (i.e., the tendency to seek to comprehend the perspective of others; Davis, 1983). Figure 1 displays our proposed theoretical model and demonstrated that we consider how averages in authentic living and perspective taking complement each other to foster information elaboration within the team and ultimately team performance.

Insert Figure 1 about here.

Our work contributes to the literature in at least three ways. First, we answer the calls to broaden the study of authenticity from a predominant focus on individual-level effects to explore more collective outcomes (Roberts et al., 2009). Specifically, by exploring the implications of authenticity for team functioning, we not only shift the level of analysis but break new theoretical ground by studying new mediators (information elaboration within the team). Developing such a team-level view of the effects of authenticity is important because in the workplace individuals often don't work in isolation (Chen, 2019; Opie \& Freeman, 2017) but in a coordinated fashion to achieve common objective. This begs the question whether, beyond the established individual benefits, authenticity also serves the larger collective (Cha et al., 2019).

Second, our model responds to previous calls to provide a more nuanced understanding of authenticity's generally accepted positive effects (e.g., Ibarra, 2015; Pfeffer, 2015). Whereas prior work has generally demonstrated positive outcomes for being authentic at work (Cha et al., 2019), our work is one of the few to suggest a potential downside to authenticity. Specifically, we suggest it takes the counterbalancing influence of a relational variable like perspective taking to curb the potential risks and bring out the potential of a self-oriented variable like authenticity.

Finally, our work aids in teasing apart the effects of various interpretations of authenticity (Hicks, Schlegel, \& Newman, 2019). For instance, some multi-component conceptualizations of authenticity include resistance to any type of external influence (e.g., Wood et al., 2008) such that authenticity may seem opposite to taking another's perspective (Goncalo \& Krause, 2010). Others, however, argued that authenticity does not need to signal independence from or opposition to one's environment (Deci \& Ryan, 2000; Kernis, 2003) and that one's own and others' perspectives can co-exist peacefully. We follow that reasoning and argue that authenticity and perspective taking complement each other to help teams complete their interdependent tasks.

\section{Theory and Hypotheses}

\section{Authentic Living: Expressing one's True Self in Behavior}

The literature on authenticity is rich (Hicks et al., 2019) and it's multidisciplinary nature has created struggles in reaching conceptual clarity, leading some to suggest that "there are as 
many definitions of authenticity, as there are those who write about it" (Erickson, 1995, p. 123). To shed light on this issue, Cha et al. (2019) provided an overview of existing conceptualizations that suggest two complementary insights. On the one hand, there seems to be some convergence in the literature such that most contemporary definitions of authenticity emphasize the "alignment between a person's internal sense of self and outward behavior (Caza et al., 2017; Harter, 2002; Roberts, Cha, Hewlin, \& Settles, 2009).” (p. 4). Similarly, in our work, we align with this conceptual core and use the conceptualization of authentic living as "behaving and expressing emotions in such a way that is consistent with the conscious awareness of physiological states, emotions, beliefs, and cognitions" (Wood et al., 2008, p. 386).

On the other hand, Cha et al. (2019) pointed to the value of considering different interpretations of authenticity for distinct research questions. For instance, Gino, Kouchaki, and Galinsky (2015) focused on feeling inauthentic (i.e., self-alienation; Wood et al., 2008) as it relates to feelings of immorality and Hewlin (2009) focused more on authenticity as opposing conformity (not accepting external influence, Wood et al., 2008) as it relates to emotional exhaustion and intentions to leave. Similarly, for our research question pertaining to teamwork, a focus on a behavioral manifestation of authenticity (authentic living) is important. After all, the effects of authenticity on interdependent processes are likely to stem from expressions of one's authenticity that are apparent to others. Consistent with Cha et al. (2019) and to be clear on our conceptualization, we consistently use the term "authentic living" in the remainder of our paper.

\section{Team Mean Authentic Living as a Compositional Measure of Team Personality}

In this study, we follow others (e.g., Kernis \& Goldman, 2006; Wood et al., 2008) in conceptualizing and measuring authentic living as a stable tendency of individuals to act in accordance with their values, thoughts, and feelings across time and situations (thus contrasting it with more state feelings of authenticity ${ }^{1}$ ). More specifically, we chose to focus on trait authentic living and members' additive composition on this trait (i.e., averages in authentic living across the team) as a driver of team outcomes.

Prior research has highlighted that several compositional models (e.g., mean, variance, maximum, or minimum) can be used to study the effects of team trait composition on team outcomes (Bell, 2007). Kozlowski and Bell (2003) suggested that the choice of the most appropriate aggregation model should be theoretically informed. In this regards, the classification of tasks by Steiner (1972) has argued that team information elaboration (and the tasks that stand to benefit from it) is additive in nature. Hence, elaboration benefits from all members engaging in the sharing, discussion, and integration of members' information and perspectives (e.g., Homan et al., 2008; van Knippenberg, Kooij-de Bode, \& van Ginkel, 2010) rather than being highly contingent on the strongest or weakest link or benefitting from diversity. In line with these

\footnotetext{
${ }^{1}$ Some authors have conceptualized authenticity as a state, defined as the experience of expressing one's authentic self in a particular context (e.g., Roberts et al., 2009; Sedikides, Slabu, Lenton, \& Thomaes, 2017). For instance, Kahn (1990) suggested that the extent to which one feels that one can express one's true and full self may vary, for example, following the degree to which a certain work environment allows for feelings of psychological safety. In this paper however we do not look at individual (Kahn, 1990) or shared (Edmondson, 1999) perceptions of the extent to which one feels as one can express oneself in a particular environment (or for that matter shared perceptions of "team authenticity").
} 
considerations, we deliberately rely on an additive or summary index model (Chan, 1998; Chen, Mathieu, \& Bliese, 2004) of aggregating authentic living to the team level.

\section{Team Mean Authentic Living and Team Information Elaboration}

Team information elaboration has been defined as the exchange, discussion and integration of information relevant to the task (van Knippenberg, De Dreu, \& Homan, 2004). Team mean authentic living can be a double-edged sword for team information elaboration. On the one hand, high levels of authentic living may benefit information elaboration: In teams high in authentic living, individuals reveal their inner thoughts, perspectives, and feelings to others (Kernis \& Goldman, 2006; Wood et al., 2008) such that the team will likely have a lot of perspectives and knowledge of its members mobilized and available. This provides the necessary contributions for teams to combine and elaborate upon these unique perspectives (van Knippenberg et al., 2004). High-level team mean authentic living may therefore ultimately create a foundation for effective team functioning.

On the other hand, high team mean authentic living is no guarantee for team information elaboration to occur. It is not because the unique perspectives of authentic individuals are revealed that those ideas will also be picked up and elaborate upon by others. Teams with a high level of overall authentic living might risk a state of confusion and even frustration if ideas are brought to the table but not actively picked up and used to move the team's thinking forward. This in turn can hinder team performance because the available information is not combined or elaborated upon in a way that produces better outcomes. Instead, members' contributions remain merely a lineup of unique perspectives (Gardner, Gino, \& Staats, 2012; Hinsz et al., 1997).

This double-edged influence suggests that the effects of team mean authentic living on elaboration are contingent on the extent to which members exhibit a complementary focus on listening to the perspectives of their colleagues and integrating them into the team's thinking. Next we suggest the role of team mean perspective taking to help better understand these effects.

\section{The Moderating Role of Team Mean Perspective Taking}

Perspective taking can be defined as an individual's tendency to spontaneously understand and adopt the psychological point of view of others (Davis, 1983). In contrast to authentic living, which focuses on expressing one's own perspective, perspective taking refers to trying to understand the world from the vantage point of others (Galinsky, Ku, \& Wang, 2005). Similar to authentic living, we look at perspective taking as a trait (i.e., as an individual difference variable) and aggregate this variable to look at the average level of perspective taking in the team (see also Longmire \& Harrison, 2018). Like trait authentic living, the effect of trait perspective taking can emerge from all members of the team. We expect that team mean perspective taking is key to leverage the potential positive effects of team mean authentic living on information elaboration and to counterbalance its potential negative effects.

When team mean perspective taking is high, team members investigate, discuss and try to understand each other's' perspectives (Parker, Atkins, \& Axtell, 2008). This causes an overlap in team members' cognitive structures (Davis, Conklin, Smith, \& Luce, 1996; Galinsky et al., 2005; 2008). Team members whose cognitive structures share more common elements, will be more open to each other's influence, and more willing to discard, alter or combine their own and others' perspectives in function of generating high-quality solutions. This promotes sharedness and convergence in the group. Additionally, when trying to understand each other's' perspectives, team members will be prompted into deeper, more complex styles of thinking. This in turn allows them to process information more thoughtfully, thoroughly, and effectively (Gruenfeld, 1995; Gruenfeld, Thomas-Hunt, \& Kim, 1998). Finally, perspective taking has been found to lead people 
to tailor their messages to aid the comprehension of recipients (Krauss \& Fussell, 1991) which should aid a team discussing different members' views.

We advance that high team mean perspective taking is complementary to high authentic living such that teams benefit from having high levels of both. Particularly when team members are inclined to express their own ideas and feelings (i.e., high authentic living) and value each other's perspectives (i.e., high perspective taking), high levels of team information elaboration occur. In contrast, when team mean authentic living is high, but team mean perspective taking is low, the contributed information risks to remain a lineup of isolated perspectives, hindering team information elaboration because, team members get confused and even frustrated when their perspectives are brought forward but not taken into account. The mere presence of multiple perspectives is thus not the key, it is essential to combine and integrate these unique contributions (Hinsz et al., 1997; van Knippenberg et al., 2004). We thus predict:

Hypothesis 1: Team mean perspective taking moderates the effect of team mean authentic living on team information elaboration, such that authentic living relates positively (negatively) with information elaboration for high (low) perspective taking.

\section{The Link to Team Performance}

Prior work has shown that information elaboration is an essential condition for team performance (e.g., Homan et al., 2007; Kearney, Gebert, \& Voelpel, 2009). We therefore argue that the exchange of information and perspectives and the discussion and integration of perspectives allow teams to devise better and more creative solutions and decisions (De Dreu, Nijstad, van Knippenberg, 2008; van Knippenberg, 2017). In other words, because elaboration does not merely reflect information sharing but also captures how teams proceed using this information, elaboration is a particularly potent predictor of performance-related outcomes in teams. We therefore aim to confirm extant findings and hypothesize:

Hypothesis 2: Team information elaboration is positively related to team performance.

\section{Integrated Model}

Our full hypothesized model (see also Figure 1) reflects the idea that the team means of authentic living and perspective taking personality present two essential, complementary ingredients for team information elaboration and therefore team performance to occur. To function optimally, teams need to process information effectively by promoting both members contributions such that members bring forward their different perspectives as well integrating those different perspectives into a whole that exceeds the sum of its parts (Hinsz et al. 1997). When team members authentically express their perspectives, they contribute unique information to the group. When team members try to understand the perspectives of others, they are deepening the information generated by others. This more extensive consideration of the relevant information utilizes the resources that the various members bring to the table (Wang, 2015) and translates into a process of information elaboration at the group level. This team-level process of constructively discussing each other's suggestions and integrating the input provided by different members (van Knippenberg et al., 2004) explains why a high mean level of both team authentic living and perspective taking may affect team performance indirectly through information elaboration. In other words, the process of team information elaboration is necessary to understand whether authentic living in the team is of benefit or potential detriment to team performance. Summarized, we expect that team information elaboration will mediate the interactive effects of team mean authentic living and team level perspective taking on team performance. We therefore extend the previous hypotheses with: 
Hypothesis 3: Team mean perspective taking moderates the indirect effect of team mean authentic living on team performance via team information elaboration.

\section{Study 1 - Method \\ Data Collection}

535 undergraduate university students were randomly assigned to a team as part of coursework and received the opportunity to sign up for a teambuilding workshop to improve their relationships. The teambuilding exercise used in our workshop has been used in past research (Homan et al., 2007; Johnson \& Johnson, 1982; Jordan \& Troth, 2014; Wang, 2015). In this exercise, students are presented with the scenario that their plane has crash-landed in the Canadian wilderness, leaving them just a few items to survive (i.e., a small axe). Students rank-order the items themselves and then engage in a group discussion to develop a joint solution. To see how teams performed, team rankings are compared to expert rakings. Typically, in this exercise, the team ranking is more similar to the expert ranking than the individual ranking, as no single team member has the resourcefulness to think of the variety of ways to use an item.

Participation was voluntary, but students received credit for participation. In total, 349 students participated. Two weeks before the workshop, students were sent a unique link (to allow matching of respondents across time) to an online questionnaire collecting information on members' authentic living and perspective taking. Two weeks later, students engaged in the workshop. At the end of the workshop, we asked to assess team information elaboration.

We took several steps to ensure high quality data. For instance, we excluded respondents with missing data for one or more of the items (i.e., we only considered complete responses) and/or suspicious response patterns (e.g., so for instance all "4", completed exceptionally fast). Additionally, in line with prior work on team composition (e.g., Kearney et al., 2009; Kearney \& Gebert, 2009; Richter, Hirst, van Knippenberg, \& Baer, 2012), we excluded teams with less than $50 \%$ response. These various steps to ensure data quality bring the final number of respondents used for data analysis to 247 (71\% of the workshop sample) organized in 67 teams.

As this workshop was offered within one undergraduate program cohort, our participants (60\% female) were relatively young $(M=21.24)$ and showed minimal variance in age $(S D=.37)$. The majority identified themselves as Dutch and living in the Netherlands (45\%), or from another European country (30\%), and $25 \%$ originated from outside of Europe. The majority of our students were interested in a career in finance and accounting (40\%) and strategy (30\%) next to smaller percentages in operations, marketing, and human resource management.

\section{Measures}

Team Mean Authentic Living. We assessed authentic living with the 4-item subcomponent of the authentic personality scale of Wood et al. (2008) rated on a 5-point Likertscale, ranging from $1=$ strongly disagree to 5 = strongly agree. An example item is: "I live in accordance with my values and beliefs." The Cronbach's alpha for this scale was .85. Individual member scores were averaged to the team level. In line with our focus on personality traits and our prior arguments that aggregation in this case is best modelled following a summary index model (Chan, 1998; Chen, Mathieu, \& Bliese, 2004), we neither assumed nor tested for agreement among members' authentic living.

Team Mean Perspective Taking. In an effort not to overtax our respondents' attention, we relied on the four highest loading items from the perspective taking scale included in Davis' (1980; 1983) Interpersonal Reactivity Index to measure individuals' habitual tendency to adopt the point of view of others. An example item reads: "I sometimes try to understand my group 
members better by imagining how things look from their perspective". Participants recorded their answers using a 5-point Likert scale ranging from $1=$ totally disagree to $5=$ totally agree. The items formed a scale of satisfactory internal consistency (Cronbach alpha $=.66$ ) and were aggregated to the team level following a summary index model.

Team Information Elaboration. We used the 4-item scale of elaboration of task-relevant information by Kearney et al. (2009). An example item reads: "The team members complemented each other by openly sharing their knowledge". The Cronbach alpha was .81. All items were measured on a 5-point Likert scale ranging from $1=$ totally disagree to $5=$ totally agree. The ratings provided by each member were aggregated across team members. Because individual members were asked to rate the behavior of their team as the higher-order referent, team information elaboration represents a referent-shift model of aggregation. The members' interrater agreement (median $\left.r_{w g}=.92\right)$ and reliability $(\operatorname{ICC}(1)=.16 ; \operatorname{ICC}(2)=.56)$ justified this aggregation (Bliese, 2000).

Team Performance. Team performance was objectively assessed at the end of the workshop by subtracting the team's ranking of the items from the expert ranking. The sum of the absolute difference indicated how different the team ratings were from the expert rating. Because lower scores reflected better performance, this measure was reverse coded for easier interpretation such that higher scores indicate higher performance.

Control Variables. In this study, we were interested in the overall capacity of the team to engage in authentic behaviors and perspective taking (i.e., the team mean levels representing members' tendency to display authentic living and perspective taking). Yet, the same mean value on each of these traits could be the result of different patterns of variance. In order to rule out that this variance in composition affects our results, we controlled for the team standard deviations of authentic living and perspective taking. Additionally, considering that we use a compositional model for authentic living and perspective taking, we considered the response rate per team as a control variable. A lower or higher average of team mean authentic living or team mean perspective taking may be biased by the overall response rate in the team.

\section{Study 1 - Results}

We first we ran a CFA using the Mplus Statistical Software where we distinguished the focal variables of authentic living, perspective taking, and information elaboration. As shown in Table 1, this model showed a good fit (Hu \& Bentler, 1998; 1999): $\chi^{2}(51)=75.49(p=.02), S R M R$ $=.05, R M S E A=.04, C F I=.97$, which was superior to the fit of various other models. Table 2 displays means, standard deviations, and correlation coefficients of the variables. We ran a path model at the team level of analysis which showed a good fit to the data: $\chi^{2}(3)=.98(p=.81)$, $S R M R=.02, R M S E A=.01, C F I=.99$. As shown in Figure 2 , team mean authentic living $(\beta=.07$, $n s)$ and perspective taking were unrelated $(\beta=.08, n s)$ to team information elaboration, but in support of Hypothesis 1 we found a significant interaction effect $(\beta=.35, p<.01)^{2}$. Figure 3 demonstrates that the association of team mean authentic living with team information elaboration is positive for high (i.e., $1 \mathrm{SD}$ above the mean) $(b=.26, p=.01)$ and negative for low (i.e., $1 \mathrm{SD}$ below the mean) team mean perspective taking $(b=-.16, p=.01)$.

Furthermore, our model provided support for Hypothesis 2 stating that team information elaboration is a predictor of team performance $(\beta=.36, p<.01)$. To test our moderated mediation hypothesis (Hypothesis 3), we used the procedure outlined by Preacher, Rucker, and Hayes (2007)

\footnotetext{
${ }^{2}$ We found that adding control variables to our model did not significantly alter the interpretation of our findings. For sake of brevity, these tables are available on request.
} 
and bootstrapped the indirect effect of team authentic living on team performance at different values of team perspective taking, using a 95\% confidence interval. The results fail to support Hypothesis 3: We find a positive indirect effect for high (indirect effect $=.30, \mathrm{CI}:[-.15 ; .90]$ ) and low (indirect effect $=-.18$, CI: $[-.53 ; .04]$ ) team mean perspective taking, these effects were not significant. Table 3 summarizes these conditional indirect effects.

Insert Table 1, 2, and 3 and Figure 2 and 3 about here

The results of Study 1 provide first evidence for our assumptions that teams which score high in authentic living benefit from high levels of perspective taking in terms of team information elaboration. Unfortunately, the indirect effects on team performance were not statistically significant. One potential explanation for these insignificant results is the nature of the teams: These students were grouped into newly formed teams that had worked together for only a limited time to complete the task at hand. This lack of prior collaboration may have weakened the potential effects on team information elaboration and ultimately on team performance. For team mean authentic living and team mean perspective taking to have more pronounced effects, the team may need a longer working relationship such that the team really gets into a habit of integrating the different perspectives that team members bring forward.

A second reason for the lack of a significant indirect effects might be the nature of the task under investigation. The performance measure under investigation here looks at wilderness survival. Considering that none of the students were experts in survival, the differences in perspectives that authentic team members might have brought forward to bear on team information elaboration and team performance might be limited. Furthermore, although the outcome of this task is "objective" in that they are compared to an expert rating, this measure is also limited as it does not account for the multitude of factors that drive team performance. For instance, in real life team performance may not only be a matter of making certain decisions, but also be a function of the team's ability to implement the suggested ideas. For these reasons, we decided to run a second study in an organizational context with more traditional measures of team performance for teams that had been working together for a longer period of time.

\section{Study 2 - Method Data Collection}

In Study 2, participants were sampled from established teams within a large Belgian retail company. Teams were considered if they were composed of one team leader and a minimum of three members who reported directly to this leader. For practical reasons (time and workload), we asked an HR representative to randomly select the number of participating leaders and followers in their organization that would not hinder daily operations. The representative provided the email addresses of 1044 followers reporting to 59 leaders.

We contacted respondents through e-mail and asked them to complete a web-based survey. We sent a reminder after two weeks. Respondents received unique survey links to match data across two phases. At Phase 1, followers rated their levels of authentic living and perspective taking personality. At Phase 2, two months later, leaders rated team information elaboration and team performance. Similar to Study 1, when investigating the data quality, we excluded respondents with (1) incomplete responses, (2) suspicious response patterns, and (3) teams where less than $50 \%$ of the total team responded. After cleaning the data based on these criteria, the average response rate was $67 \%$ within teams. The final sample consisted of 194 respondents (19\% of the original sample), organized in 37 teams. 
Team members' average age was 36.74 years $(S D=8.24)$ and $39 \%$ were women. They had a tenure of 8.78 years on average $(S D=7.34)$, and had worked on average in the same function for 6.34 years $(S D=7.36)$. Leaders' average age was 40.22 years $(S D=9.53)$ and $22 \%$ were women. They had a tenure of 15.19 years on average $(S D=7.97)$, and had worked in the same function for 8.96 years on average $(S D=4.34)$.

\section{Measures}

Team Mean Authentic Living, Perspective Taking, and Information Elaboration. These constructs were measured as in Study 1 ( $\alpha$ 's were.73, .67, and 79, respectively). All items were measured on a 7 -point Likert scale ranging from $1=$ totally disagree to $7=$ totally agree .

Team Performance was measured using four items of goal attainment, a subscale of team effectiveness (Gibson, Zellmer-Bruhn \& Schwab, 2003). An example items is "My team fulfills its mission." The Cronbach alpha was .80. All items were measured on a 7-point Likert scale ranging from $1=$ totally disagree to $7=$ totally agree .

Control variables. Similar to Study 1, we controlled for the standard deviation of authentic living and perspective taking as well as the response rate per team. Additionally, in this second study, we controlled for measures of self-alienation and not accepting external influence (Woods et al., 2008). While we align with others that more precise constructs form the basis of more careful theorizing and more empirical results (Lemoine, Hartnell, \& Leroy, 2019; van Knippenberg \& Sitkin, 2013), we wanted to make sure our results did not depend on factors that others have associated with authenticity. We measured these using the respective subcomponents Woods et al. (2008) scale on a 7-point Likert scale ranging from $1=$ totally disagree to $7=$ totally agree . Example items are "I feel alienated from myself." (self-alienation; $\alpha=.88$ ) and "Other people influence me greatly." (accepting external influence; $\alpha=.76$ ).

\section{Study 2 - Results}

We assessed the measurement model differentiating our focal variables of authentic living, perspective taking, self-alienation, and accepting external influences. As shown in Table 4, this model showed a good fit (Hu \& Bentler, 1998; 1999): $\chi^{2}(98)=135.49(p=.01)$, SRMR $=.06$, $R M S E A=.04, C F I=.97$. Our hypothesized model fitted better than any other model.

Table 5 displays means, standard deviations, and correlation coefficients of the variables included in this study. We ran a path model at the team level of analysis, using aggregated data. This model showed a good fit: $\chi^{2}(3)=1.41(p=.62), S R M R=.03, R M S E A=.01, C F I=.99$. As depicted in Figure 4 and in support of Hypothesis 1, we found positive associations for team mean authentic living $(\beta=.37, p<.01)$, team mean perspective taking $(\beta=.29, p<.05)$, and their interaction $(\beta=.74, p<.01)$ in the prediction of team information elaboration. ${ }^{3}$ As displayed in Figure 5, the association of mean authentic living with team information elaboration is positive for high (i.e., $1 \mathrm{SD}$ above the mean) mean perspective taking $(b=.73, p=.01)$ and negative for low (i.e., $1 \mathrm{SD}$ below the mean) mean perspective taking $(b=-.26, p=.01)$.

Furthermore, we demonstrate that team information elaboration is a predictor of team performance $(\beta=.46, p<.01)$, which provides support for Hypothesis 2 . To test our moderated mediation hypothesis (Hypothesis 3), we estimated the indirect effect of team mean authentic living on team performance through team information elaboration at different values of team perspective taking using a 95\% confidence internal (Preacher et al., 2007). In partial support of

\footnotetext{
${ }^{3}$ We found that adding control variables to our model did not significantly alter the interpretation of our findings. For sake of brevity, these tables are available on request.
} 
Hypothesis 3, we found that the indirect effect was significant when the team was high in perspective taking (indirect effect $=.22$, CI: $[.03, .61]$ ), and not significant when the team was low in perspective taking (indirect effect $=-.07, \mathrm{CI}:[-.25, .07]$ ) . Table 6 summarizes the conditional effects on team information elaboration as well as on team performance

Insert Table 4, 5, and 6 and Figure 4 and 5 about here

\section{Discussion}

The present study examined the effect of the team average in authentic living on team performance via team information elaboration. Across two field studies (one with teams of students and one among teams of employees), we found that the self-oriented concept of authentic living and the other-oriented concept of perspective taking could be distinguished by means of CFA and that the correlations between both constructs were low, ranging from negative $(r=-.15)$ in study 1 to positive $(r=.22$,) in study 2 . This confirms the idea that both constructs are conceptually distinct to each other. This is important as prior work has suggested that authenticity may be equated with independence or resistance to external influence (Wood et al., 2008). We however align with others (e.g., Deci \& Ryan, 2000) that one can be authentic in a way that still is mindful of the perspective of others.

Beyond highlighting their conceptual distinction, we argued that in an organizational context that requires coordinated action between team members; both authentic expression of one's own perspective and taking the perspective of others are important to the successful completion of interdependent tasks. We confirmed that the benefits of team mean authentic living for teams elaboration of the perspective present in the team are dependent on whether teams score high versus low in perspective taking such that teams high in authentic expression of their perspectives only elaborate on the available information when they also score high in perspective taking. In the employee sample, teams high in authentic expression and perspective taking also performed better because they engaged in more information elaboration of the various perspectives in the team. In the student sample, this indirect effect on team performance was in the proposed direction, but failed to reach significance.

In this paper, we move beyond the well-established benefits of individuals' authenticity on personal well-being (e.g., Cha et al., 2019) by analyzing the implications of team mean authentic living on interdependent team processes and outcomes. This necessitates not only a new theoretical lens on the effects of authenticity (i.e., the groups as information processors model; Hinsz et al., 1997) but also offers insights that extend previous knowledge.

First, our findings allow us to provide an answer to the question whether we can extend the frequently repeated advice of be 'true to self' to a workplace context, which is characterized by collaboration and teamwork (Cha et al., 2019). Our results clearly indicate that teams benefit from combining high levels of authenticity with high levels of perspective taking. Within the context of teamwork, the advice to be true to self should thus be complemented with the advice to pay attention to other's perspectives, in a way that both are present in the overall team. Indeed, sharing unique perspectives, thoughts and feelings may benefit team performance, but only when team members also invest effort to try and understand each other's contributions.

Our results also hint towards the possibility that high levels of authenticity can become a social liability in work teams. Without the complementary effects of perspective taking teams with high levels of members' authentic living may fail to engage in the full subset of processes that lead into team information elaboration. Moreover, scoring high on authenticity, teams may even fail to 
engage in information elaboration, as team members could get stuck in their own perspectives and start blocking or hindering their colleagues' input. We thus advance that authenticity in a work context is not without risks and join other authors in expressing caution towards the unequivocal encouragement of authenticity at work (e.g., Ibarra, 2015; Opie \& Freeman, 2017; Pfeffer, 2015; Rosh \& Offerman, 2013).

Our study on the interplay of authenticity and perspective taking also offers a more finegrained understanding of how information elaboration occurs in a team. The construct of information elaboration has mostly been discussed in the context of diversity in teams (e.g., Hoever et al., 2012; Homan et al., 2007; van Knippenberg et al., 2004). Our analysis of elaboration through the lens of groups as information processors leads us to consider another team characteristic that might drive elaboration. Indeed, the quality of the discussion, elaboration and integration of information also depends on the level of authenticity in the team. When team members are not inclined to express their unique perspectives, thoughts and feelings, or when they tailor them to the perspectives of their colleagues too quickly, suboptimal information elaboration will occur (even regardless of the team's diversity). In this regard, authenticity provides an interesting lens to prior work on team diversity and team performance. Team diversity will not influence team performance unless this diversity is enacted.

Our integrated model further confirms and extends the idea of groups as information processors (De Dreu, Nijstad, \& van Knippenberg, 2008; Hinsz et al., 1997). Specifically, our theory and model suggests that for effective elaboration of information to occur it is important to include both a self-oriented (i.e., authentic living) and other-oriented (perspective taking) angle. Although some have argued for the importance of a prosocial orientation for effective team functioning (De Dreu et al., 2008, Hoever et al., 2012), others advanced the importance of a selforiented focus (Goncalo \& Staw, 2006; Goncalo \& Krause, 2010). In this paper, we establish the importance of both foci as information elaboration requires different perspectives to be brought to the fore as well as the elaboration of these perspectives. Team mean authentic living and perspective taking make sure that these two essential functions are fulfilled.

\section{Limitations and Avenues for Future Research}

First, future studies could adopt a more fine-grained analysis that looks at the different components of the elaboration processes. Such studies could potentially substantiates our argument that authenticity promotes sharing, but not understanding and integration, whereas perspective taking fosters these latter two components of information elaboration. Although our paper suggested that this may be the case, future research needs to examine this using more precise analyses, for instance by looking at network measures of advocacy and inquiry (reference). A social network analysis (e.g., Cross, Borgatti, \& Parker, 2002) could further help tease out specific patterns of interaction in the team as a result of authenticity and perspective taking. For instance, imagine a team where all team members high in authenticity are interconnected, and all team members high in perspective taking are interconnected, but no connections between those teams. Imagine another team where multiple connections between high authentic and high perspective taking team members exist. Although the team mean of both teams can be exactly the same, we would expect the second team to have higher team results.

Second, despite this confirmation of our theoretical ideas, our mediation effects are not always significant. Given the strong evidence between information elaboration and team performance in prior work (Hoever et al., 2012; 2018; Homan et al., 2007; Kearney et al., 2009; Samba et al., 2018; van Ginkel \& van Knippenberg, 2008, 2009), we believe that the most likely 
explanation for the inconsistent mediation evidence in our study is methodological. Specifically, our reliance on survey measures of elaboration (which may be less accurate than observational measures; Weingart, 1997) may have reduced the power of our tests. Similarly, while smaller sample sizes are not uncommon for team-level studies (Shen et al.; 2011), future research would clearly benefit from larger samples to enhance statistical power.

Our findings across two studies enhance our confidence in the quality of the central idea of this work that the effects of team mean authenticity depend on team mean perspective taking. However, as indicated earlier, there are some limits to the generalizability of our findings. For instance, we indicated a difference in strength of the relationships between the student and the employee sample. This should caution the reader that these effects may not be generalizable in the same way to all types of jobs and industries. Furthermore, although the employees in our sample performed a wide variety of jobs (e.g., service, logistics, managerial), we studied employees in only one industry (retail). We would be interested to learn whether our model holds in a context varying in job autonomy. Would similar processes play when team members have more freedom (e.g., a team of consultants), or - in contrast - have very clear and aligned tasks (e.g., an assembly line) or where all team members are expected to follow orders blindly (e.g., the army)? Systematic replications - in different sectors and companies - would answer the question of whether our results generalize to other work settings.

Practical Implications

Despite these clear limitations and various suggestions for future research, our findings have significant practical implications. Foremost the most obvious way to create effective teams in organizations is through careful selection of team members. Team members need to be selected so that teams are sufficiently high both in mean authenticity and mean perspective taking. This way, the team can meet the dual demands of effective team information processing.

Our results are also important for team leaders, who need to facilitate high performing teams. Besides through recruitment and selection, team leaders can build teams combining high levels of authenticity and perspective taking, by creating an environment where team members are given space to express their inner world and feel appreciated when exploring other's contributions - a psychologically safe environment. Considering the stable nature of traits (reference), we do not expect team psychological safety as fostered by the leader to directly influence authentic and perspective taking personalities. Instead, we expect that team psychological safety may strengthen the effects of the team's innate tendencies towards authenticity and perspective taking on team information elaboration. In line with trait activation theory (Tett \& Burnett, 2003) and whole trait theory (Fleeson \& Jayawickreme, 2015), we need to be aware that traits that are present, will not always and automatically be enacted. Leaders and the broader organizational environment (e.g., a climate for inclusion that emphasizes both expressing a diversity of perspectives as well as appreciating the diversity that was expressed; Nishii, 2013) can help create an environment where authenticity and perspective taking are appreciated and rewarded (Edmondson \& Lei, 2014).

Our work also has important practical implications in terms of improving teamwork. For employees in teams, our findings support the importance of acknowledging that both authenticity and perspective taking are crucial to achieve a team's potential. In teams facing a lineup of perspectives where nobody is trying to understand the information, a team member should realize that he/she contributes most to the team by discussing and trying to understand the already available perspectives. Even if this means the team member must refrain from his/her inclination to express his/her inner perspectives, thoughts and feelings. Alternatively, in teams lacking new information, team members can contribute most by being authentic. Teams can use the insights 
expressed in this paper to help overcome a difficult working relationship or a team coach can use these insights to unlock a team's full potential. 


\section{Conclusion}

Overall, for organizations, our findings call for a more nuanced approach to the advice of "being true to oneself" (e.g., George, 2003; Rosenbloom, 2011). Behaving in line with one's true self is important. The promise of team work lies not in the mere presence of multiple people, but in them actually contributing and sharing their perspectives and ideas to the team. However, teams do not perform when they merely lineup perspectives. They also need the combination and integration of the available information, pointing at the importance of perspective taking at work. Self-oriented and other-oriented tendencies in an organization such as being authentic and taking other's perspective thus do not have to impede, but can instead enhance each other. These insights can help organizations to move beyond oversimplified notions of team processes and as such aptly respond to the complex and ambiguous challenges of organizational life. 


\section{References}

Aiken, L.S., \& West, S.G. (1991). Multiple regression: Testing and interpreting interactions. New York, NY: Sage.

Anderson, J. C., \& Gerbing, D. W. (1988). Structural equation modelling in practice: A review and recommended two-step approach. Psychological Bulletin, 103, 411-423.

Baugh, S. G., \& Sullivan, S. (2012). Research in careers: Searching for authenticity. Charlotte, NC: Information Age Publishing.

Bell, S. T. (2007). Deep-level composition variables as predictors of team performance: A metaanalysis. Journal of Applied Psychology, 92, 595-613.

Bliese, P. D. (2000). Within-group agreement, non-independence, and reliability: Implications for data aggregation and analysis. In K. J. Klein \& S. W. J. Kozlowski (Eds.), Multilevel theory, research, and methods in organizations: Foundations, extensions, and new directions (pp. 349-381). San Francisco, CA, US: Jossey-Bass.

Boland, R. J., \& Tenkasi, R. V. (1995). Perspective making and perspective taking in communities of knowing. Organization Science, 6, 350-372.

Caza, B. B., Moss, S., \& Vough, H. (2017). From Synchronizing to harmonizing: The process of Authenticating multiple work identities. Administrative Science Quarterly, 63, 703-745.

Cha, S., Hewlin, P., Roberts, L., Buckman, B., Leroy, H., Steckler, E., Ostermeier, K., \& Cooper, D. (2019). Being your true self at work: Integrating the fragmented research on authenticity in organizations. Academy of Management Annals, 13, 633-671.

Chan, D. (1998). Functional relations among constructs in the same content domain at different levels of analysis: A typology of composition models. Journal of Applied Psychology, 83, 234-246.

Chen, G., Mathieu, J. E., \& Bliese, P. B. (2004). A framework for conducting multi-level construct validation. Research in Multi-Level Issues, 3, 273-303.

Chen, S. (2019). Authenticity in Context: Being True to Working Selves. Review of General Psychology, 23, 60-72.

Cross, R., Borgatti, S.P., \& Parker, A. (2002). Making invisible work visible: Using Social Network Analyis to support strategic collaboration. California Management Review, 44(2), 25-46.

Davis, M. H., Conklin, L., Smith, A., \& Luce, C. (1996). Effect of perspective taking on the cognitive representation of persons: A merging of self and other. Journal of Personality and Social Psychology, 70, 713-726.

Davis, M. H. (1980). A multidimensional approach to individual differences in empathy. Catalog of Selected Documents in Psychology, 10, 85.

Davis, M. H. (1983). Measuring individual differences in empathy: Evidence for a multidimensional approach. Journal of Personality and Social Psychology, 44, 113-126.

Deci, E., \& Ryan, R. (2000). Self-determination theory and the facilitation of intrinsic motivation, social development, and well-being. The American Psychologist, 55(1), 68-78.

De Dreu, C., Nijstad, B., \& van Knippenberg, D. (2008). Motivated information processing in group judgment and decision making. Personality and Social Psychology Review, 12(1), 22-49.

Edmondson, A. (1999). Psychological safety and learning behavior in work teams. Administrative Science Quarterly, 44(2), 350-383. 
Edmondson, A., \& Lei, Z. (2014). Psychological safety: The history, renaissance, and future of an interpersonal construct. Annual Review of Organizational Psychology and Organizational Behavior, 1, 23-43.

Erickson, R. J. (1995). The importance of authenticity for self and society. Symbolic Interaction, $18,121-144$.

Erickson, R. J., \& Ritter, C. (2001). Emotional labor, burnout, and inauthenticity: Does gender matter? Social Psychology Quarterly, 64(2), 146-163.

Fleeson, W., \& Jayawickreme, E. (2015). Whole trait theory. Journal of Research in Personality, 56, 82-92.

Galinsky, A. D., Ku, G., \& Wang, C. S. (2005). Perspective-taking and self-other overlap: Fostering social bonds and facilitating social coordination. Group Processes \& Intergroup Relations, 8(2), 109-124.

Galinsky, A. D., Wang, C. S., \& Ku, G. (2008). Perspective-takers behave more stereotypically. Journal of Personality and Social Psychology, 95(2), 404- 419.

Gardner, H. K., Gino, F., \& Staats, B. R. (2012). Dynamically integrating knowledge in teams: A resource-based view of team performance. Academy of Management Journal, 55(4), 998998.

George, B. (2003). Authentic leadership: Rediscovering the secrets to creating lasting value. San Francisco, CA: Jossey-Bass.

George, B., \& Sims, P. (2007). True North. Discover your Authentic Leadership. San Francisco, CA: John Wiley \& Sons.

Gebert, D., Boerner, S., \& Kearney, E. (2010). Fostering team innovation: Why is it important to combine opposing action strategies? Organization Science, 21(3), 593-608.

Gibson, C. B., Zellmer-Bruhn, M. E., \& Schwab, D. P. (2003). Team effectiveness in multinational organizations: Evaluation across contexts. Group and Organization Management, 28(4), 444-474.

Gino, F., Kouchaki, M., \& Galinsky, A. D. (2015). The moral virtue of authenticity: How inauthenticity produces feelings of immortality and impurity. Psychological Science, 26(7), 983-996.

Gino, F., Sezer, O., \& Huang, L. (in press). To be or not to be your authentic self? Catering to others' preferences hinders performance. Organizational Behavior and Human Decision Processes.

Gruenfeld, D. H. (1995). Status, ideology, and integrative complexity on the U. S. Supreme Court: Rethinking the politics of political decision making. Journal of Personality and Social Psychology, 68, 5-20.

Gruenfeld, D. H., Thomas-Hunt, M., \& Kim, P. H. (1998). Divergent thinking, accountability, and integrative complexity: Public versus private reactions to majority and minority status. Journal of Experimental Social Psychology, 3, 202-226.

Goncalo, J., \& Krause, V. (2010). Being different or being better?: Disentangling the effects of independence and competition on group creativity. Advances in Group Processes, 27, 129157.

Goncalo, J. A., \& Staw, B. M. (2006). Individualism-collectivism and group creativity. Organizational Behavior and Human Decision Processes, 100, 96-100.

Hannah, S., Walumbwa, F., \& Fry, L. (2011). Leadership in action teams: Team leader and members' authenticity, authenticity strength, and team outcomes. Personnel Psychology, 64(3), 771-771. 
Harter, S. (2002). Authenticity. In C. R. Snyder, \& S. Lopez (Eds.), Handbook of positive psychology (pp. 382-394). Oxford: Oxford University Press.

Hewlin, P. F. (2009). Wearing the cloak: Antecedents and consequences of creating facades of conformity. Journal of Applied Psychology, 94, 727-741.

Hicks, J. A., Schlegel, R. J., \& Newman, G. E. (2019). Introduction to the Special Issue: Authenticity: Novel Insights Into a Valued, Yet Elusive, Concept. Review of General Psychology, 23(1), 3-7.

Hinsz, V. B., Tindale, R. S., \& Vollrath, D. A. (1997). The emerging conceptualization of groups as information processors. Psychological Bulletin, 121(1), 43-64.

Hoever, I. J., van Knippenberg, D., van Ginkel, W. P., \& Barkema, H. G. (2012). Fostering team creativity: Perspective taking as key to unlocking diversity's potential. Journal of Applied Psychology, 97(5), 982-996.

Homan, A. C., van Knippenberg, D., van Kleef, G. A., \& De Dreu, C. K. W. (2007). Bridging faultlines by valuing diversity: Diversity beliefs, information elaboration, and performance in diverse work groups. Journal of Applied Psychology, 92(5), 1189-1199.

Homan, A. C., Hollenbeck, J. R., Humphrey, S. E., Knippenberg, D. V., Ilgen, D. R., \& Van Kleef, G. A. (2008). Facing differences with an open mind: Openness to experience, salience of intragroup differences, and performance of diverse work groups. Academy of Management Journal, 51(6), 1204-1222.

Hu, L., \& Bentler, P. M. (1998). Fit indices in covariance structure modeling: Sensitivity to underparameterized model misspecification. Psychological Methods, 3, 424-453.

Hu, L., \& Bentler, P. M. (1999). Cutoff criteria for fit indexes in covariance structure analysis: Conventional criteria versus new alternatives. Structural Equation Modeling, 6, 1-55.

Ibarra, H. (2015). The Authenticity Paradox. Harvard Business Review, 93(1/2), 52-59.

Ilgen, D. R., Hollenbeck, J. R., Johnson, M., \& Jundt, D. (2005). Teams in organizations: From input-process-output models to IMOI models. Annual Review of Psychology, 56, 517-543.

James, W. (1890). Principles of psychology, vols. 1 \& 2. New York: Holt.

Jehn, K. A., Northcraft, G. B., Neale, M. A., Quarterly, A. S., \& Dec, N. (1999). Why Differences Make a Difference : A Field Study of Diversity, Conflict, and Performance in Workgroups. Administrative Science Quarterly, 44(4), 741-763.

Johnson, D. W., \& Johnson, F. P. (1982). Joining together: Group theory and group skills (2nd ed.). Englewood Cliffs, NJ: Prentice Hall.

Jordan, P. J., \& Troth, A. C. (2004). Managing emotions during team problem solving: Emotional intelligence and conflict resolution. Human Performance, 17, 195-218.

Kahn, W. A. (1990). Psychological conditions of personal engagement and disengagement at work. Academy of Management Journal, 33, 692-724.

Kearney, E., Gebert, D., \& Voelpel, S. C. (2009). When and how diversity benefits teams: The importance of team members' need for cognition. Academy of Management Journal, 52, $581-598$.

Kernis, M. H. (2003). Toward a conceptualization of optimal self-esteem. Psychological Inquiry, 14(1), 1-26.

Kernis, M. H., \& Goldman, B. M. (2006). A multicomponent conceptualization of authenticity: Theory and research. In M. P. Zanna (Ed.), Advances in experimental social psychology, 38(6), 283-357. 
Kooij-de Bode, H., Van Knippenberg, D., \& Van Ginkel, W. (2010). Good effects of bad feelings: Negative affectivity and group decision-making. British Journal of Management, 21(2), 375-375.

Kozlowski, S. W. J., \& Bell, B. S. (2003). Work groups and teams in organizations. In W. C. Borman, D. R. Ilgen, \& R. J. Klimoski (Eds.), Handbook of psychology: Industrial and organizational psychology, Vol. 12, (pp. 333-375). Hoboken, NJ, US: John Wiley \& Sons Inc.

Ku, G., Wang, C. S., \& Galinsky, A. D. (2015). The promise and perversity of perspective-taking in organizations. Research in Organizational Behavior, 35, 79-102.

Lemoine, J., Hartnell, C., \& Leroy, H. (2019). Taking stock of moral approaches to leadership: An integrative review of ethical, authentic and servant leadership. Academy of Management Annals, 13(1), 148-187.

Leroy, H., Anseel, F., Dimitrova, N. G., \& Sels, L. (2013). Mindfulness, authentic functioning, and work engagement: A growth modeling approach. Journal of Vocational Behavior, 82(3), 238-247.

Lewis, M. W. (2000). Exploring paradox: Toward a more comprehensive guide. Academy of Management Review, 25, 760-777.

Longmire, N., \& Harrison, D. (2018). Seeing their side versus feeling their pain: Differential consequences of perspective-taking and empathy at work. Journal of Applied Psychology, 103(8), 894-894.

Maslow, A. H. (1968). Toward a psychology of being (2nd ed.). New York, NY: Van Nostrand Reinhold.

Opie, T. R., \& Freeman, R. E. (2017). Our biases undermine our colleagues' attempts to be authentic. Harvard Business Review. Retrieved from https://hbr.org/2017/07/our-biasesundermine-our-colleagues-attempts-to-be-authentic.

Parker, S. K., Atkins, P. W. B., \& Axtell, C. M. (2008). Building better work places through individual perspective taking: A fresh look at a fundamental human process. In G. Hodgkinson \& K. Ford (Eds.). International Review of Industrial and Organizational Psychology, 1, 149-196.

Pfeffer, J., (2015). Leadership BS: Fixing workplaces and careers one truth at a time. New York: HarperCollins.

Preacher, K.J., Rucker, D.D., \& Hayes, A.F. (2007). Assessing moderated mediation hypotheses: Theory, methods, and prescriptions. Multivariate Behavioral Research, 42, 185-227.

Richter, A.W., Hirst, G., van Knippenberg, D. and Baer, M. (2012) "Creative self-efficacy and individual creativity in team contexts: cross-level interactions with team informational resources." Journal of Applied Psychology, 97(6), 1282-1290

Roberts, L. M., Cha, S. E., Hewlin, P. F., \& Settles, I. H. (2009). Bringing the inside out: Enhancing authenticity and positive identity in organizations. In L. M. Roberts \& J. E. Dutton (Eds.), Exploring positive identities and organizations: Building a theoretical and research foundation (pp. 149-170). New York: Routledge, Taylor \& Francis Group.

Rogers, C. R. (1961). On becoming a person: A therapist's view of psychotherapy. Boston, MA: Houghton Mifflin Harcourt.

Rosenbloom, S. (2011). Authentic? Get real. The New York Times. Retrieved from http://www.nytimes.com/2011/09/11/fashion/for-only-the-authentic-culturalstudies.html.

Rosh, L. \& Offermann, L. (2013). Be yourself, but carefully. Harvard Business Review Magazine. Retrieved from http://hbr.org/2013/10/be-yourself-but- carefully/ar/1. 
Samba, C., Van Knippenberg, D., \& Miller, C. (2018). The impact of strategic dissent on organizational outcomes: A meta-analytic integration. Strategic Management Journal, 39(2), 379-402.

Salas, E., Goodwin, G. F., \& Burke, C. S. (2008). Team Effectiveness in Complex Organizations: Cross-disciplinary Perspectives and Approaches. Mahwah, NJ: Lawrence Erlbaum Associates.

Sedikides, C., Slabu, L., Lenton, A., \& Thomaes, S. (2017). State authenticity. Current Directions in Psychological Science, 26(6), 521-525.

Shen, W., Kiger, T. B., Davies, S. E., Rasch, R. L., Simon, K. M., \& Ones, D. S. (2011). Samples in applied psychology: Over a decade of research in review. Journal of Applied Psychology, 96(5), 1055-1064.

Slabu, L., Lenton, A. P., Sedikides, C., \& Bruder, M. (2014). Trait and state authenticity across cultures. Journal of Cross-Cultural Psychology, 45, 1347-1373.

Smith, W. K., \& Lewis, M.W. (2011). Toward a theory of paradox: A dynamic equilibrium model of organizing. Academy of Management Review, 336(2), 381-403.

Steiner, I. (1972). Group process and productivity (Social psychology). New York, NY: Academic Press.

Tett, R., \& Burnett, D. (2003). A Personality Trait-Based Interactionist Model of Job Performance. Journal of Applied Psychology, 88(3), 500-517.

van Ginkel, W. P., \& van Knippenberg, D. (2008). Group information elaboration and group decision making: The role of shared task representations. Organizational Behavior and Human Decision Processes, 105(1), 82-97.

van Ginkel, W. P., \& van Knippenberg, D. (2009). Knowledge about the distribution of information and group decision making: When and why does it work? Organizational Behavior and Human Decision Processes, 108(2), 218-229.

van Knippenberg, D., De Dreu, C. K., \& Homan, A. C. (2004). Work group diversity and group performance: An integrative model and research agenda. Journal of Applied Psychology, 89(6), 1008-1022.

van Knippenber, D. \& Sitkin, S. B. (2013). A Critical Assessment of CharismaticTransformational Leadership Research: Back to the Drawing Board?. The Academy of Management Annals, 7(1), 1-60.

Wang, S. (2015). Emotional intelligence, information elaboration and performance: The moderating role of informational diversity. Small Group Research, 46(3), 324-351.

Wood, A. M., Linley, P. A., Maltby, J., Baliousis, M., \& Joseph, S. (2008). The authentic personality: A theoretical and empirical conceptualization and the development of the Authenticity Scale. Journal of Counseling Psychology, 55(3), 385-399. 
Table 1

Comparative Fit Indices for Alternative Confirmatory Factor Analyses of Measurement Model for Study 1

\begin{tabular}{|c|c|c|c|c|}
\hline & $\chi^{2}$ & CFI & SRMR & RMSEA \\
\hline 1. Hypothesized Model & $\chi^{2}(51)=75.49$ & .97 & .05 & .04 \\
\hline 2. All Items Loading on Single Factor & $\chi^{2}(54)=551.64$ & .47 & .16 & .19 \\
\hline 3. Authenticity and Perspective Taking Loading on Single Factor & $\chi^{2}(53)=247.21$ & .79 & .14 & .12 \\
\hline
\end{tabular}


Table 2

Means, Standard Deviations and Intercorrelations for Study 1

\begin{tabular}{llcccccccc}
\hline & & M & SD & 1 & 2 & 3 & 4 & 5 & 6 \\
\hline 1 & SD Authenticity & .73 & .32 & & & & & \\
2 & SD Perspective Taking & .47 & .27 & .10 & & & & \\
3 & Response Rate/Team & .74 & .14 & .03 & $.36^{* *}$ & & & & \\
4 & Team Mean Authentic Living & 3.19 & .41 & $.43^{* *}$ & -.06 & -.20 & & -.05 & $-.15^{*}$ \\
5 & Team Mean Perspective Taking & 4.79 & .26 & .04 & .01 & .10 & -.15 & $.43^{* *}$ \\
6 & Team Information Elaboration & 4.17 & .30 & -.08 & -.17 & .01 & -.04 & .23 & \\
7 & Team Performance & 2.18 & .96 & .03 & -.18 & .02 & .05 & .13 & $.36^{* *}$
\end{tabular}

Note. * Correlation significant at .05** Correlation significant at .01. Individual level correlations on the opposite side of the diagonal. $\mathrm{N}=67$ at the team level and $\mathrm{N}=247$ at the individual level. 
Table 3

Conditional Direct and Indirect Effects of Team Mean Authentic Living on Team Performance at High and Low Levels of Team Mean Perspective Taking for Study 1

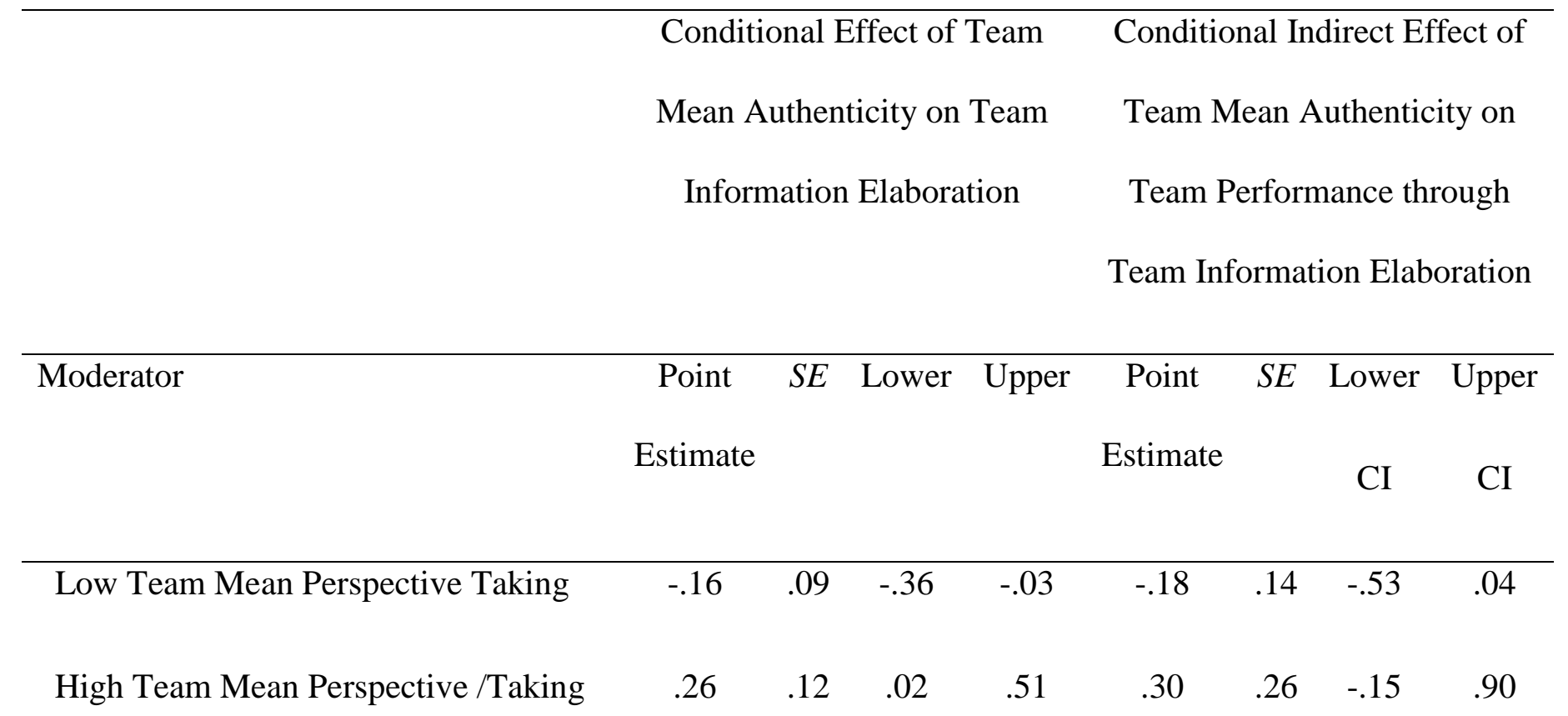

Note. Bias-corrected (BC) 95\% confidence intervals (Preacher et al., 2007) are used to interpret significance of the effect sizes. 
Table 4

Comparative Fit Indices for Alternative Confirmatory Factor Analyses of Measurement Model for Study 2

\begin{tabular}{|c|c|c|c|c|}
\hline & $\chi^{2}$ & CFI & SRMR & RMSEA \\
\hline 1. Hypothesized model & $\chi^{2}(98)=135.49$ & .97 & .06 & .04 \\
\hline 2. Authentic Living and Perspective Taking Loading on Single Factor & $\chi^{2}(101)=243.50$ & .87 & .09 & .09 \\
\hline 3. Perspective Taking and Accepting Influence Loading on Single Factor & $\chi 2(101)=383.37$ & .74 & .14 & .12 \\
\hline
\end{tabular}


Table 5

Means, Standard Deviations and Intercorrelations for Study 2

\begin{tabular}{|c|c|c|c|c|c|c|c|c|c|c|c|}
\hline & & $\mathrm{M}$ & $\mathrm{SD}$ & 1 & 2 & 3 & 4 & 5 & 6 & 7 & 8 \\
\hline 2 & SD Perspective Taking & .80 & .32 & $.60 * *$ & & & & & & & \\
\hline 3 & Response Rate/Team & .67 & .16 & $.37 *$ & .12 & & & & & & \\
\hline 4 & Team Mean Self-Alienation & 2.71 & .43 & .03 & -.06 & .07 & & $.68 * *$ & .04 & .02 & \\
\hline 6 & Team Mean Authentic Living & 5.75 & .50 & $-.44 * *$ & $-.51 * *$ & .05 & -.04 & .01 & & $.22 * *$ & \\
\hline 7 & Team Mean Perspective Taking & 4.94 & .34 & -.08 & -.08 & .12 & -.16 & -.16 & $.33^{*}$ & & \\
\hline 8 & Team Information Elaboration & 5.50 & .37 & .16 & .14 & -.23 & -.03 & .10 & .03 & .14 & \\
\hline 9 & Team Performance & 5.71 & .36 & $.49 * *$ & $.35^{*}$ & -.01 & -.20 & .03 & .07 & $.32 *$ & $.46 * *$ \\
\hline
\end{tabular}

Note. * Correlation significant at .05** Correlation significant at .01. Individual level correlations on the opposite side of the diagonal. $\mathrm{N}=37$ at the team level and $\mathrm{N}=194$ at the individual level. 
Table 6

Conditional Direct and Indirect Effects of Team Mean Authentic Living on Team Performance at High and Low Levels of Team Mean Perspective Taking for Study 2

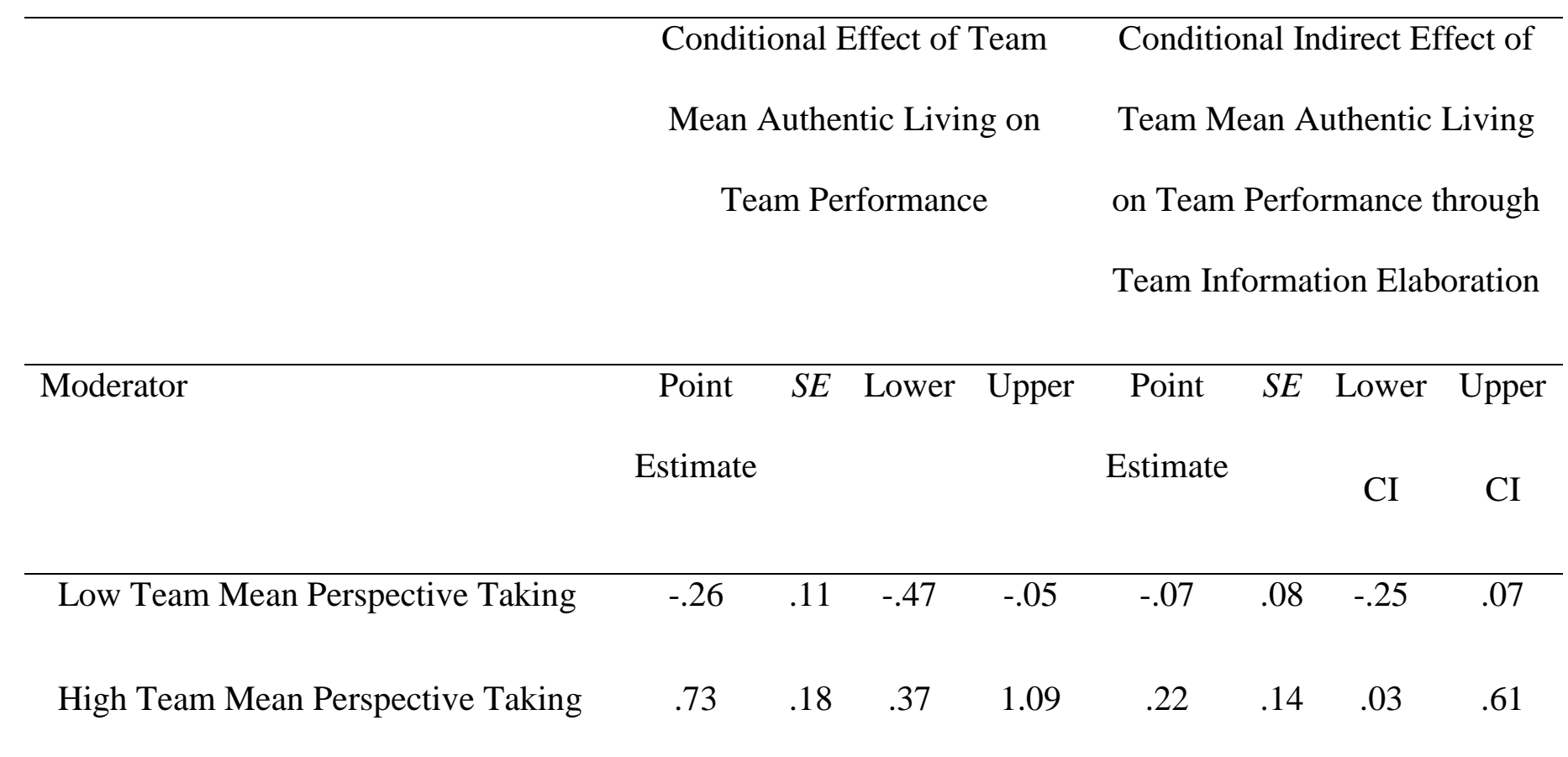

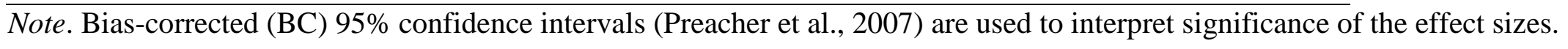




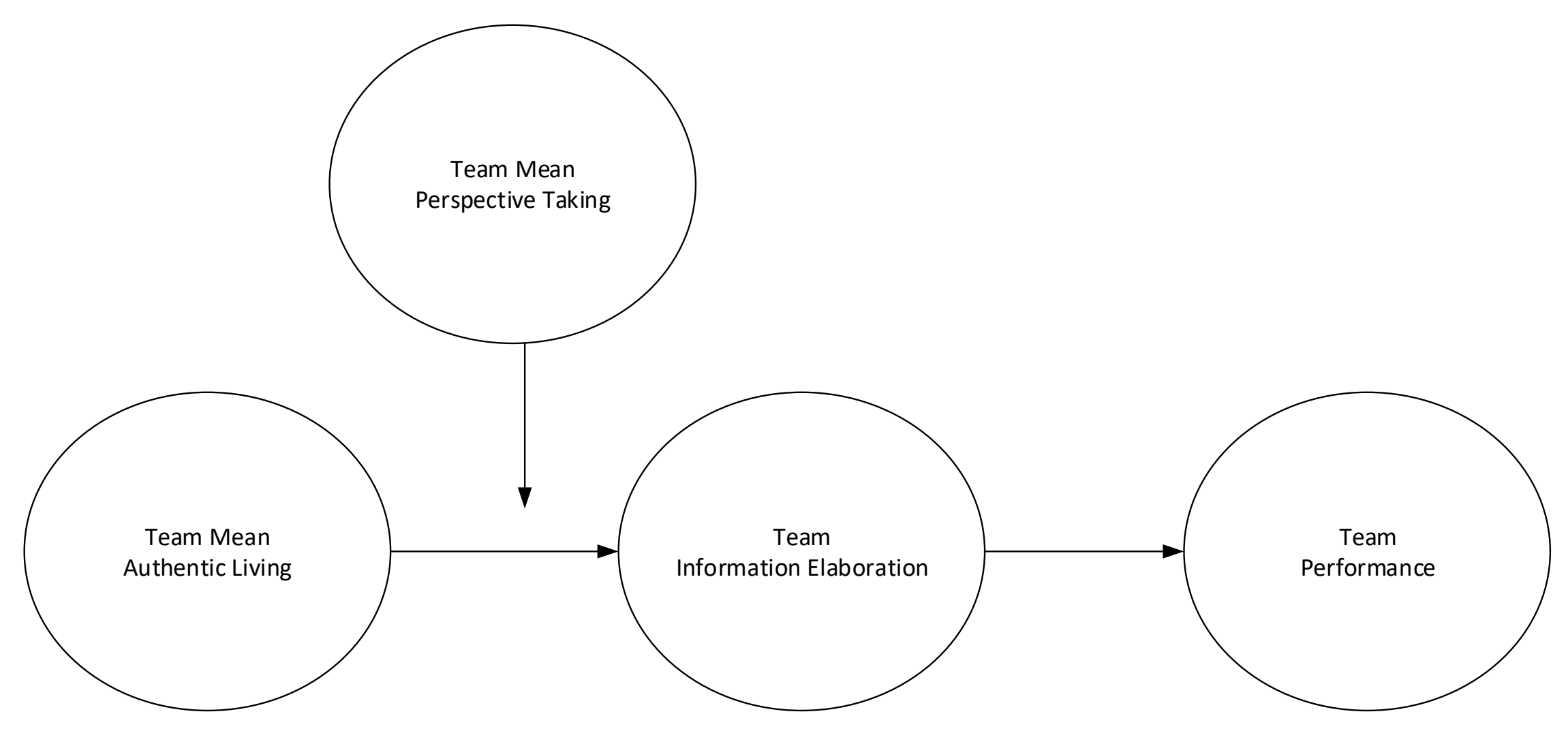

Figure 1. Hypothesized model. 


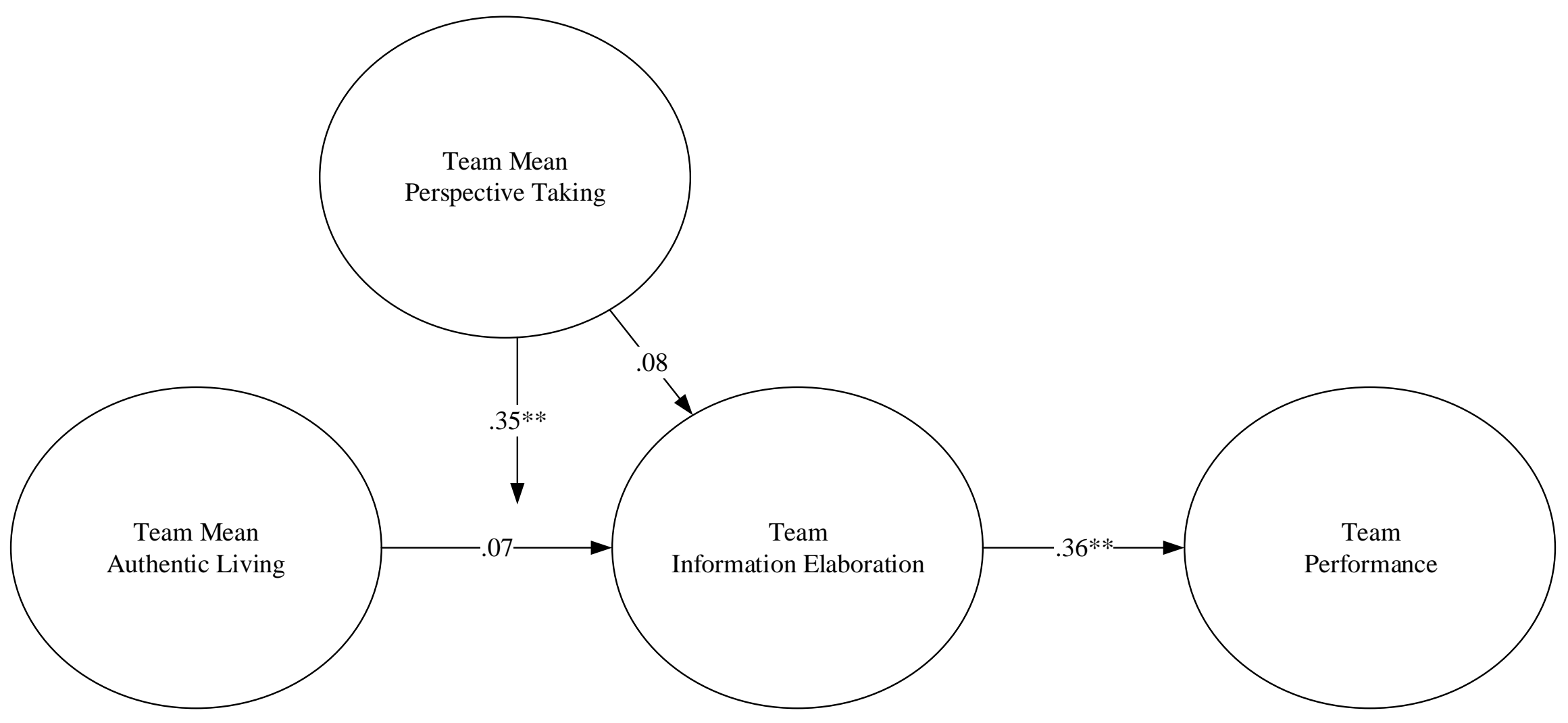

Figure 2. Standardized Effects in Path Model for Study 1. 


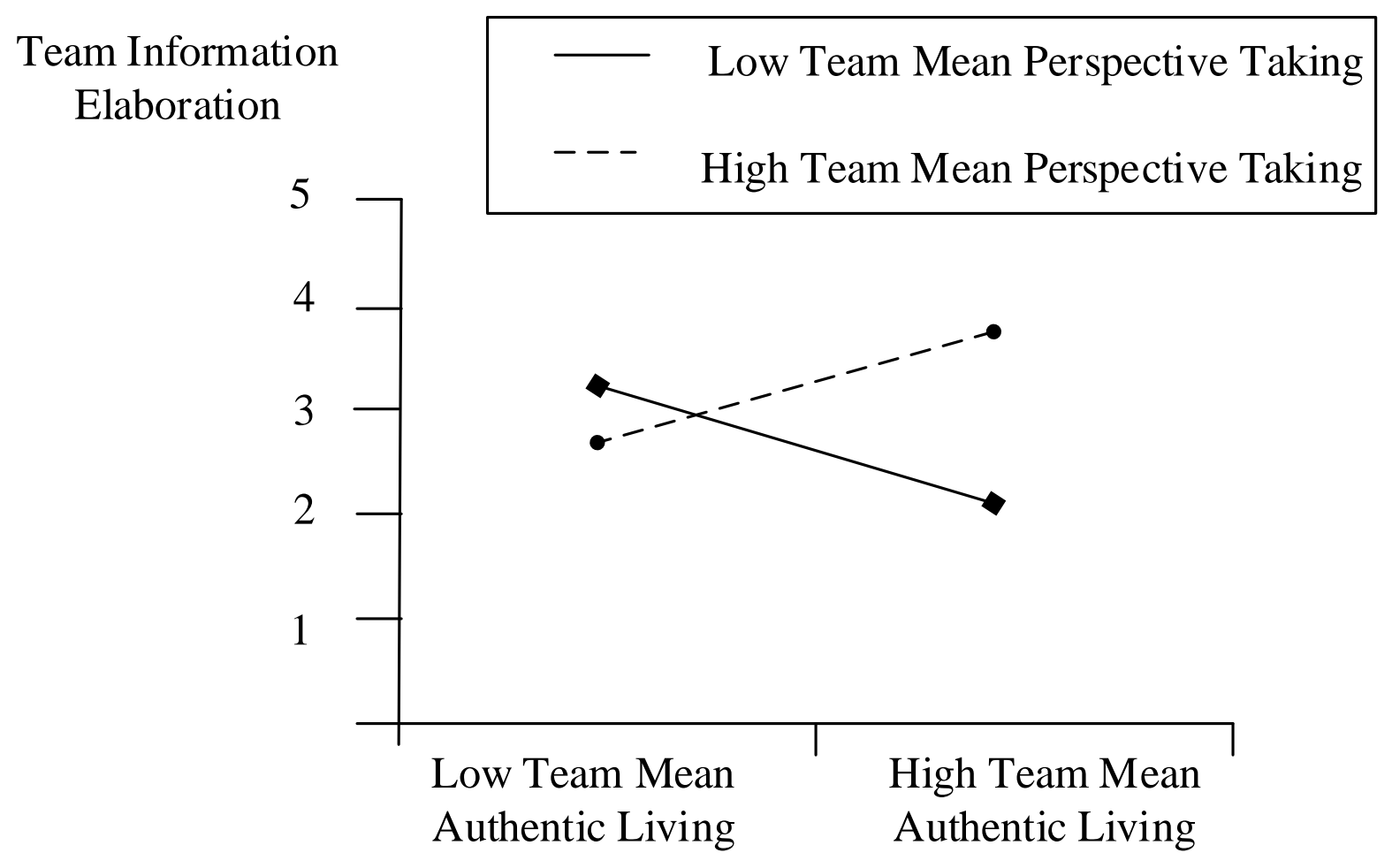

Figure 3. Interaction Effect between Team Mean Authentic Living and Team Mean Perspective Taking on Team Information Elaboration for Study 1. 


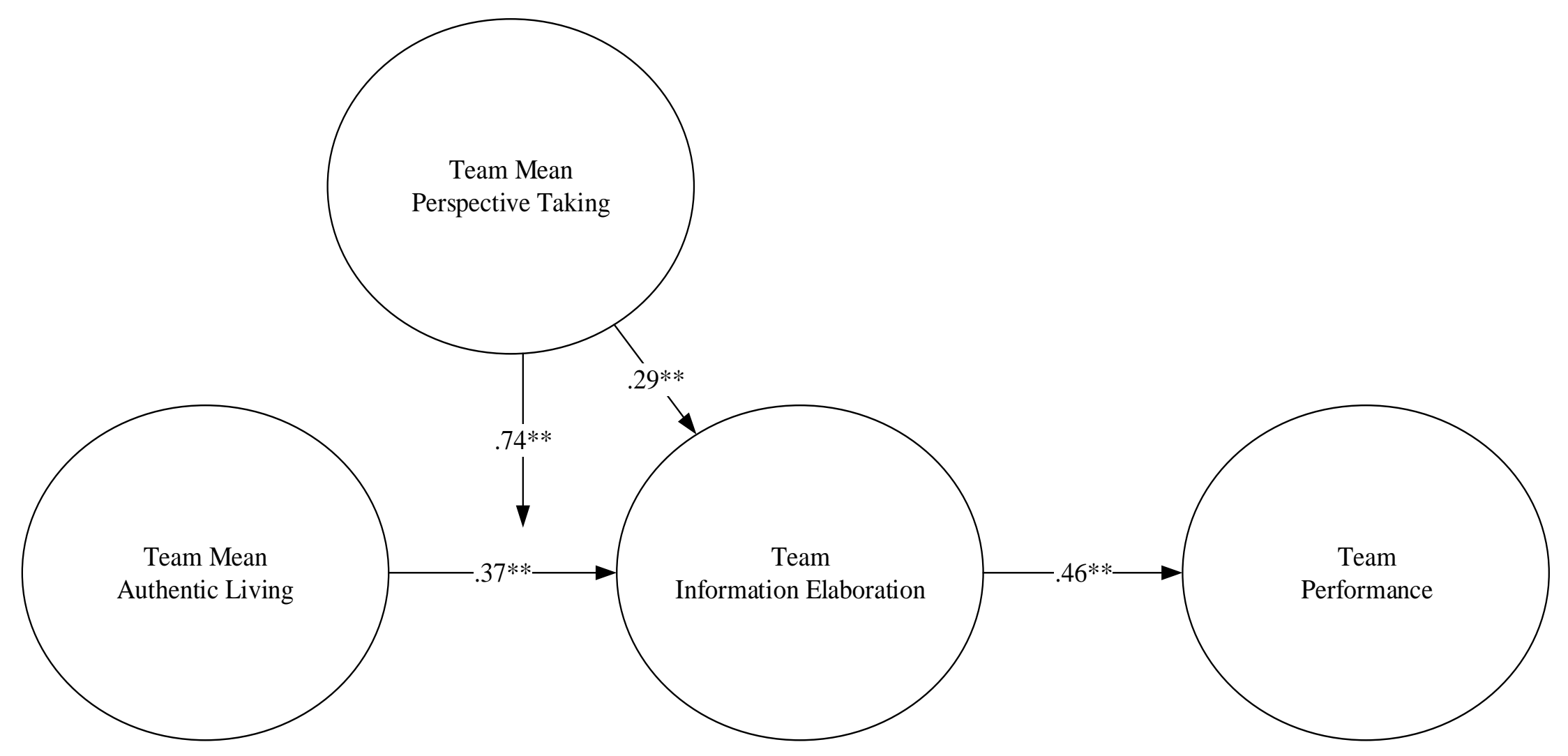

Figure 4. Standardized Effects in Path Model for Study 2. 


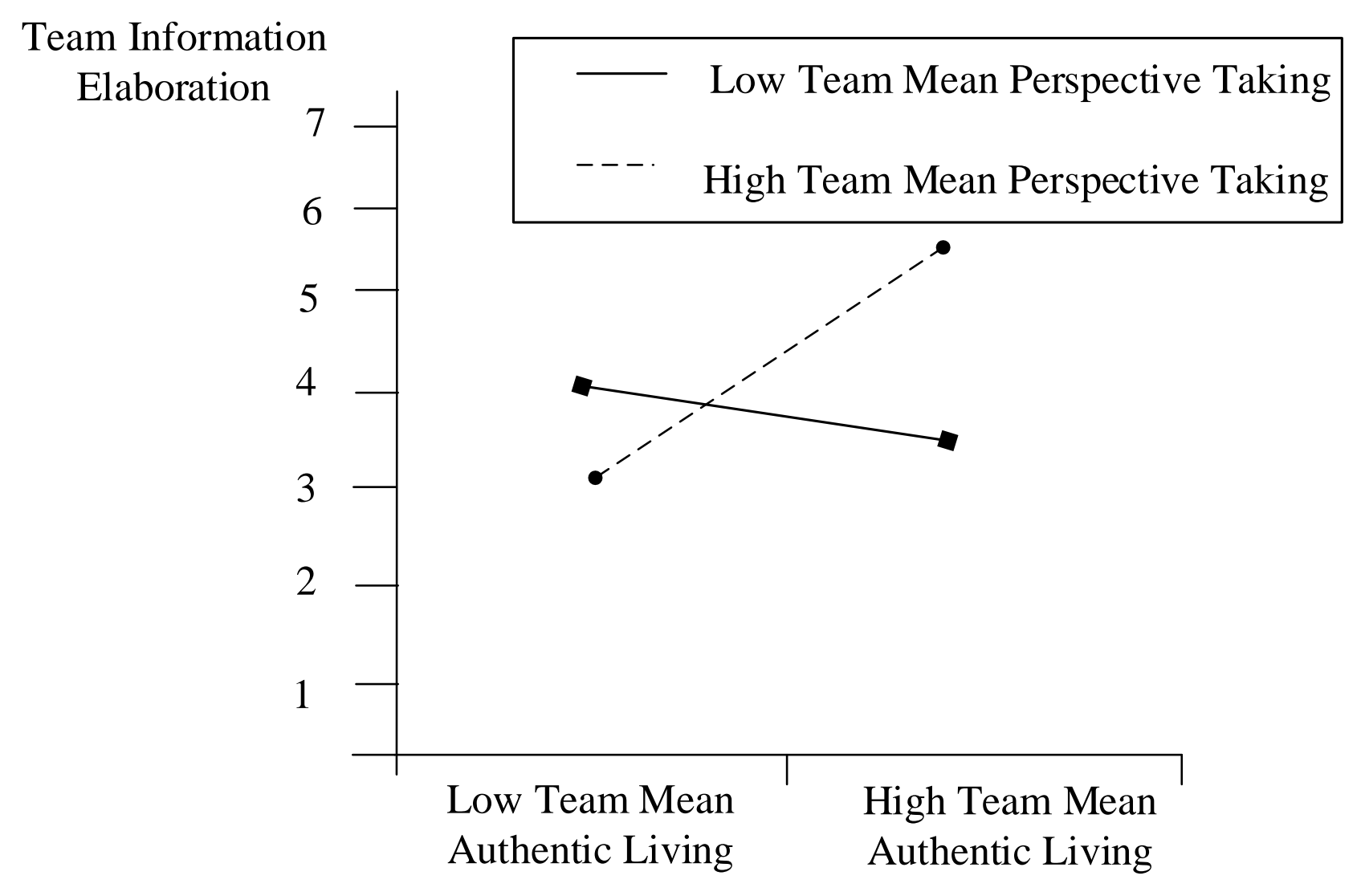

Figure 5. Interaction Effect between Team Mean Authentic Living and Team Mean Perspective Taking on Team Information Elaboration for Study 2. 